\title{
Globalización y ciudad: la reinvención de espacios urbanos en América Latina
}

\author{
Emilio José Luque Azcona
}

Universidad de Sevilla

\begin{abstract}
El presente trabajo analiza algunos de los principales efectos que el fenómeno de la globalización está teniendo sobre el medio urbano latinoamericano. Concretamente, la puesta en marcha por parte de gobiernos locales de proyectos de gran envergadura de cara a la atracción de inversiones y visitantes. Para ello, se describen las características principales de experiencias concretas de intervención, tanto en barrios y centros históricos como en antiguos frentes costeros urbanos, por constituir estos los principales marcos espaciales con los que algunas ciudades han pretendido la conformación de una imagen más atractiva de ellas mismas. Asimismo, se realiza un balance de los resultados obtenidos hasta el momento por este tipo de iniciativas y se tratan algunos de los conflictos que han generado en el ámbito de lo local.

Palabras Clave: Globalización, América Latina, ciudad, identidad.

The purpose of this paper is to analyse some of the main effects that the phenomenon of globalization is having on Latin American urban environment, specifically how local authorities have been implementing large scale projects policies in urban areas in order to attract investors and visitors. With this purpose some characteristics of experiences of intervention in historic quarters and waterfronts are described, as these spaces constitute the new main showcases used by several cities for the construction of a more attractive image of themselves. A balance of the results obtained until now with these initiatives and some of the conflicts arising at the local level are also included.
\end{abstract}

KEYwords: Globalization, Latin America, City, Identity

\section{Introducción}

El estudio del impacto que el fenómeno de la globalización tiene sobre el territorio latinoamericano ha centrado durante las últimas décadas la atención de numerosos investigadores de diferentes disciplinas. Desde la celebración en 1989 en Santiago de Chile de un seminario internacional relativo a esta temática, organizado de manera conjunta por el Instituto Latinoamericano y del Caribe de Planificación Económica y Social (ILPES) 
de las Naciones Unidas y el Instituto de Estudios Urbanos (IEU) de la Pontificia Universidad Católica de Chile, han sido varios los encuentros desarrollados con este fin. Desde 1994 existe incluso una Red Iberoamericana de Investigadores sobre Globalización y Territorio (RII), encargada del análisis de los cambios producidos en la "distribución territorial de las actividades económicas y de la población, difusión y adopción territorial de innovaciones tecnológicas, nuevas modalidades de gestión pública territorial y disparidades regionales y/o locales en materia de calidad de vida y de bienestar social". ${ }^{1}$

Todo ello ha permitido que en la actualidad podamos entender mejor las transformaciones que el proceso de globalización más reciente ${ }^{2}$ está teniendo sobre el medio urbano latinoamericano. No obstante, aún son muchas las incógnitas al respecto que quedan por resolver. Con este trabajo pretendemos profundizar en el estudio de una de ellas, analizando los conflictos generados a partir de la puesta en marcha de proyectos de gran envergadura, orientados en parte a dar respuesta a los retos derivados del fenómeno de la globalización. Concretamente, aquellos que se desarrollan en espacios dotados con una fuerte herencia histórica y carga simbólica, especialmente centros históricos y frentes fluviales o marítimos que sirvieron de marco para el desarrollo de actividades portuarias y/o de esparcimiento de la población en diferentes momentos del pasado. Para ello, vamos a comenzar dando una panorámica general sobre las distintas medidas que varias urbes del planeta han desarrollado de cara a posicionarse en el contexto internacional, para pasar posteriormente a analizar esta cuestión en el ámbito latinoamericano.

\section{Estrategias urbanas para competir en un mundo globalizado}

Desde la década de 1980 numerosos gobiernos locales han promovido el desarrollo de importantes transformaciones urbanas y la organización

1 Red Iberoamericana de Investigadores sobre Globalización y Territorio (RII) [en línea] <http://www.cmq.edu.mx/rii/> [15 de octubre de 2007].

2 Autores como Ankie Hoogvelt y Robbie Robertson afirman que la globalización no es un fenómeno nuevo. Éste se dio en el pasado y en la actualidad se caracteriza por la existencia de movimientos más rápidos y mayores concentraciones del capitales, así como por el incremento de las desigualdades socio-económicas. Hoogvelt, Ankie: Globalization and the Postcolonial world: the New Political Economy of Development, John Hopkins University Press, Baltimore, 2001; Robertson, Robbie: The Three Waves of Globalization: A History of a Developing Global Consciousness, Zed Books, New York, 2003. 
de grandes eventos para la atracción de inversiones y visitantes. El objetivo, convertir a sus respectivos núcleos urbanos en "ciudades globales" en el contexto del nuevo orden económico mundial, caracterizado por el incremento en la movilidad del capital, el paso paulatino hacia una economía de servicios y una mayor dependencia de las tecnologías de la información. ${ }^{3}$

Con ese objetivo, la organización de eventos de gran relevancia (juegos olímpicos, exposiciones universales, capitales de la cultura,...), la recuperación de centros históricos a gran escala, la reconversión de antiguas instalaciones industriales portuarias y/o frentes marítimos o fluviales como centros de ocio y negocios, la construcción de edificios emblemáticos por arquitectos de renombre internacional o la conformación de nuevas centralidades en los márgenes de las periferias urbanas, han constituido algunas de las estrategias más generalizadas. Iniciativas de este tipo se han visto acompañadas, en muchos casos, por el desarrollo de campañas de marketing urbano, con el objetivo de favorecer en una determinada ciudad la instalación de empresas o su consolidación como destino de congresos y turismo. ${ }^{4}$

En Estados Unidos y Europa fue, concretamente durante la década de 1980, cuando el fenómeno del city marketing adquirió un especial desarro1lo. En la primera, ciudades como Baltimore, Indianápolis, Nueva York o St. Louis, entre muchas otras, vieron en esos momentos en el marketing urbano un recurso con el que hacer frente a los momentos de crisis por los que estaban pasando. ${ }^{5}$ También lo han hecho desde entonces aquellas ciudades europeas que quieren acabar con una excesiva dependencia de la actividad agropecuaria, especialmente en países del sur del continente, y las que se encontraban azotadas por la crisis industrial vivida a partir de los años setenta. Entre estas últimas se encuentran algunas como Barcelona,

3 Sassen, Saskia: The Global City: New York, London, Tokyo, Princenton University Press, Princenton, 1991.

4 Duffy, Hazel: Competitive Cities: Succeeding in the Global Economy, Routledge, LondonNew York, 1995; Law, Cristopher M.: Urban Tourism: Attracting Visitors to Large Cities, Mansell, London, 1994; Kolb, Bonita: Tourism Marketing for Cities and Towns: Using Branding and Events to Attract Tourists, Butterworth-Heinemann, 2006; Kotler, Philip; Haider, Donald; Rein, Irving: Marketing Places, Free Press, New York, 2002; Ruiz Ballesteros, Esteban: Construcción simbólica de la ciudad. Política local y localismos. Miño y Dávila Editores, Madrid, 2000; Smith, Hedley: Marketing the City: The Role of Flagship Developments in Urban Regeneration. Taylor \& Francis, Routledge, 1993; Ward, Stephen: Selling Places: The Marketing and Promotion of Towns and Cities, 1850-2000, Routledge, 1998.

5 Kotler, Haider y Rein, Marketing Places, pág. 3. 
Bilbao, Duisburg, Glasgow, Londres o Manchester. ${ }^{6}$ Dicho fenómeno se extendió asimismo a otras regiones urbanas del planeta, destacando en este sentido algunas experiencias desarrolladas en Asia, como las de los 'tigres asiáticos', Pekín, Kuala Lumpur o más recientemente Shangai. ${ }^{7}$

Todo lo expuesto se ha visto impulsado por la tendencia de los gobiernos locales a hacerse más autónomos frente a los gobiernos nacionales y por el deseo de los primeros de fortalecer vínculos con urbes de otras regiones del planeta. ${ }^{8}$ Estas medidas se han llevado a cabo tanto en las ciudades que articulan la economía a escala mundial, como en aquellas que lo hacen a escala nacional o regional y que ocupan por ello niveles inferiores dentro de la jerarquía en el sistema mundial de ciudades. ${ }^{9}$ Como resultado de todo ello, algunas han logrado situarse en una posición más ventajosa de cara a la atracción de inversiones y turistas, han incorporado nuevos estilos de vida y han conformado nuevos paisajes arquitectónicos para albergar al poder financiero y los servicios de producción punta.

6 Experiencias como las desarrolladas en Barcelona a partir de su nombramiento como sede de los Juegos Olímpicos de 1992, se han convertido en un importante referente internacional. El "modelo Barcelona" ha sido no obstante criticado en algunos de sus aspectos por autores como Horacio Capel. Capel, Horacio: El Modelo Barcelona: un examen crítico, Ediciones del Serbal, Barcelona, 2005.

7 Kotler, Philip; Hamlin, Michael Alan; Rein, Irving y Haider, Donald H.: Marketing Asian Places: Attracting Investments, Industry and Tourism to Cities, States and Nations. John Wiley \& Sons, Singapur, 2001; Ward, Selling Places...Citado por Armas Díaz, Alejandro: "En torno a la mercadotecnia urbana: reorganización y reimaginación de la ciudad", Revista Bibliográfica de Geografía y Ciencias Sociales, Vol. XII, n. ${ }^{\circ}$ 712, Barcelona, 20 de marzo de 2007. [En línea]. $<$ http://www.ub.es/geocrit/b3w-712.htm> [25 de julio de 2007].

8 Thrift, Nigel, “A hyperactive World”, en Johnston, R. J.; Taylor, Peter J.; Watts, Michael J.: Geographies of Global Change. Remapping the World in the late twentieth Century. Blackwell, Oxford, 1995, págs. 18-35.

9 Autores como John Friedmann, Paul Knox, Peter Taylor o Saskia Sassen, entre otros, han proporcionado un interesante esquema de análisis para el entendimiento del cambio contemporáneo global mediante la world city hypothesis o hipótesis de ciudad mundial, y el concepto relacionado de global city o ciudad global. John Friedmann, concretamente, dividió el sistema mundial de ciudades en dos grandes grupos: el de los países centrales y el de los países periféricos, diferenciando dentro de ellos las ciudades "primarias" de las "secundarias", atendiendo a diferentes criterios. Entre ellos, constituir un gran centro financiero, una sede central transnacional, contar con la presencia de instituciones internacionales, tener un importante crecimiento del sector servicios avanzado, un tamaño demográfico determinado y ser un destacado centro de comunicación. Friedmann, John: "The World City Hypothesis", en Development and Change, The Hague, 1986, vol. 17, págs. 69-83; Friedmann, John: "Where we stand: a Decade of World City Research", en Knox, Paul L.; Taylor, Peter J. (eds.): World cities in a World-system. Cambridge University Press, New York, 1995; Sassen, Saskia: "Whose City is it? Globalization and the formation of new claims", en Public Culture, 8, Durham, 1996, págs. 205223; Taylor, Peter J.: "World Cities and territorial States under Conditions of contemporary Globalization: The 1999 Annual Political Geography Lecture", en Political Geography, 19, Elsevier Science, 2000, págs. 5-32. 
De este conjunto de iniciativas expuestas, vamos a centrar nuestro análisis en aquellos proyectos de reestructuración y revalorización de centros históricos y antiguos frentes portuarios. En este punto es preciso aclarar que el desarrollo de este tipo de emprendimientos no responde siempre a efectos derivados de la globalización. Lo hacen cuando se enmarcan dentro de estrategias de gran envergadura, orientadas a hacer más competitivas determinadas ciudades para la atracción de inversiones y visitantes a una escala continental o internacional. De forma paralela o exclusiva suelen responder también a efectos derivados de la coyuntura local o regional, como las presiones inmobiliarias generadas por el interés de sectores de alto y mediano poder adquisitivo por residir en esos espacios, o por las ventajas que determinadas empresas y comercios encuentran a la hora de instalar en ellos sus oficinas y negocios.

Los procesos de intervención orientados a la reestructuración y revalorización de centros históricos, a diferencia de lo que sucede con los emprendidos en antiguos frentes portuarios, no constituyen un fenómeno novedoso. Estos se dieron en el pasado, respondieron también entonces a los intereses de los grupos de poder que los impulsaron y contribuyeron en muchos casos a transformar, de manera forzada, el carácter identitario de las zonas intervenidas. Fue especialmente durante la segunda mitad del siglo XIX, cuando diferentes ciudades pusieron en marcha, a imitación de las reformas impulsadas por el Barón Haussman en París, actuaciones que ocasionaron drásticas transformaciones en el característico paisaje urbano, arquitectónico y humano de sus respectivas áreas centrales antiguas. Con iniciativas de este tipo se trató en esos momentos de dar respuesta a las necesidades derivadas del incremento de la población, los problemas de índole higiénico-sanitaria o el desarrollo de nuevos medios de transporte, como el ferrocarril. También hubo detrás de ellas intereses especulativos en operaciones como las de "destrucción-reconstrucción". ${ }^{10}$

La transformación radical experimentada por los centros tradicionales con el desarrollo de la ciudad industrial en Europa a partir de la segunda mitad del siglo XIX, desencadenó las primeras preocupaciones y quejas por la pérdida de la identidad histórica de estos espacios, todo ello en el contexto del romanticismo y los movimientos neomedievalistas. ${ }^{11}$ Fue

10 González Varas, Ignacio: Conservación de Bienes Culturales. Teoría, historia, principios y normas. Manuales Arte Cátedra, Madrid, 2005, pág. 350.

11 Ibidem, pág. 344. 
entonces también cuando las áreas centrales antiguas de algunas ciudades se convirtieron también en escenarios idóneos para el ensalzamiento de sentimientos nacionalistas, procediéndose para ello a la restauración y transformación de determinados edificios dotados de una importante carga simbólica e, incluso, a la conformación de lenguajes arquitectónicos para el reforzamiento de determinados sentimientos identitarios. ${ }^{12}$

Hubo que esperar a mediados del siglo XX para que, junto con la definición cultural de la noción de centro histórico, se aprobaran las primeras medidas legislativas y normativas que contemplan la protección de esos espacios. La Carta de Gubbio de 1960 conformaría la primera declaración de principios para la salvaguardia y saneamiento de los centros históricos, constituyéndose la experiencia italiana en el ámbito de los bienes culturales y en el sector urbanístico en un importante referente para la gestión futura de estos espacios. ${ }^{13}$

Gracias al desarrollo de una legislación y de todo un cuerpo burocrático encargado de velar por la conservación y la revitalización de los centros históricos, se ha impedido que estos espacios continúen experimentando drásticas transformaciones como las de antaño. No obstante, gran parte de las intervenciones desarrolladas en las últimas décadas para la recuperación de estos espacios de cara a la conformación de nuevos escaparates urbanos, han desencadenado también importantes modificaciones que, en ocasiones, han supuesto un cambio brusco en las características paisajísticas y culturales. En ello han influido, a nuestro parecer, factores de diferente tipo. Entre ellos, la restauración algo idealizada de inmuebles y espacios públicos, el impacto de la actividad turística y el desarrollo de procesos de gentrificación o, lo que es lo mismo, la sustitución de pobla-

12 Un ejemplo interesante en este sentido lo conformó la Old Town de Edimburgo, área que alberga algunos de los conjuntos arquitectónicos más emblemáticos del desarrollo histórico de Escocia. Junto a la restauración algo idealizada de determinados complejos edilicios, durante la segunda mitad del siglo XIX se construyeron en la zona otros en un nuevo estilo que mezclaba, de forma algo artificiosa, diferentes elementos característicos de la arquitectura escocesa. Nos referimos al Baronial, estilo aparecido a raíz del resurgimiento del interés por la historia y la identidad de Escocia. Este tipo de medidas, acompañadas por la demolición de numerosos inmuebles para la apertura de nuevas vías de comunicación y la mejora de las condiciones de salubridad, contribuyeron a generar violentas transformaciones en el característico paisaje urbano y arquitectónico de la Old Town. Para una visión general de las transformaciones experimentadas por ese área de Edimburgo en su contexto urbano consultar Edwards, Brian; Jenkins, Paul (eds.): Edinburgh. The Making of a Capital City. Edinburgh University Press, Edinburgh, 2005.

13 González Varas, Conservación de Bienes Culturales..., pág. 376. 
ción de escasos recursos por otra de mayor nivel adquisitivo en los centros de las ciudades. ${ }^{14}$

Este último aspecto se ha visto impulsado a raíz de la mejora en la apreciación para habitar en estos espacios, una vez que las inversiones realizadas han contribuido a la mejora de infraestructuras e inmuebles. Este hecho, unido a la sustitución de los comercios locales por establecimientos multinacionales y la no poco frecuente "disneyficación" del paisaje urbano, conlleva finalmente la pérdida de la singularidad, autenticidad, particularidad y especialidad, que precisamente sirvió en los inicios como reclamo para la atracción de turistas, nuevos residentes y negocios. Es lo que el geógrafo David Harvey denomina proceso de "mercantilización multinacional homogeneizadora", que termina por otorgar los beneficios del capital simbólico al que todos han contribuido, a multinacionales y a un pequeño segmento poderoso de la burguesía local. ${ }^{15}$

Este hecho contribuye, por tanto, al reforzamiento de uno de los aspectos más criticados del fenómeno de la globalización, concretamente, la tendencia a una relativa homogeneización de modos de consumo y estilos de vida. ${ }^{16}$ Sucede algo parecido, aunque sin la cuestión relativa a la expulsión de residentes de escasos recursos, con las intervenciones desarrolladas para la conformación de nuevos espacios de ocio y servicios en antiguas instalaciones portuarias, por incluir la utilización de un similar lenguaje arquitectónico, mobiliario urbano y usos en contextos geográficos y culturales muy diversos. También aquí, multinacionales y sectores de elevado poder adquisitivo son los más beneficiados con este tipo de actuaciones. ${ }^{17}$

14 El término gentrificación procede de la palabra inglesa gentrification y fue empleado por primera vez por Ruth Glass, en su trabajo titulado London, Aspects of Change, publicado en esa ciudad en 1964. Para una mayor profundización sobre el concepto de gentrificación, consultar Sargatal Bataller, Ma. Alba: "El estudio de la gentrificación", en Scripta Nova. Revista Electrónica de Geografía y Ciencias Sociales, n. ${ }^{\circ}$ 228, Barcelona, 3 de mayo de 2000 [en línea] <http://www.ub.es/geocrit/sn-9466.htm> [29 de septiembre de 2008].

15 Harvey, David: Espacios del capital. Hacia una geografía crítica. Ediciones Akal, Madrid, 2007, pág. 430.

16 Barnet, Richard; Cavanagh, John: "Homogenization of Global Culture", en Mander, Jerry; Goldsmith, Edward (eds.): The Case against the Global Economy and for a Turn toward the Local. Sierra Club Books, San Francisco, 1996, págs. 71-77.

17 Para un análisis de intervenciones realizadas en frentes portuarios localizados en diferentes ciudades del planeta, consultar la Web de The Waterfront Communities Project, en el siguiente enlace: $<$ http://www.waterfrontcommunitiesproject.org/ > [10 de septiembre de 2008]. 


\section{Experiencias en el ámbito latinoamericano}

En el caso de América Latina, la mayor parte de los países de la región han hecho importantes esfuerzos para participar competitivamente en la economía mundial en el contexto de la globalización contemporánea. ${ }^{18}$ Tras los importantes desequilibrios económicos experimentados por la región durante la década de 1980, que llevaron a un crecimiento importante de la inflación, el déficit fiscal, la deuda externa, el desempleo y los niveles de pobreza, diferentes gobiernos pusieron en marcha políticas ortodoxas o neoliberales orientadas a la eliminación de barreras frente al exterior, con el objetivo de favorecer el comercio y las inversiones. ${ }^{19}$

Este proceso de liberalización económica, caracterizado, entre otras cosas, por la puesta en marcha de políticas de privatización y desregularizaciones, supuso el inicio de la inserción de América Latina en la economía globalizada.$^{20}$ Como consecuencia de ello, se ha producido un fortalecimiento de la primacía urbana en São Paulo, Ciudad de México y Buenos Aires en el sistema urbano regional. ${ }^{21}$ Por otra parte, las ciudades pequeñas y medianas han logrado asimismo aumentar su peso específico en la región, gracias a la expansión de zonas francas y la actividad turística a gran escala. ${ }^{22}$ No obstante, esto último no se ha producido con la magnitud esperada, al no haber generado el abanico de nuevas actividades económicas relacionadas con las economías de exportación un proceso de relocalización industrial, que podría haber contribuido a equilibrar los sistemas urbanos nacionales. ${ }^{23}$

18 Menanteau Horta, Darío: "Impactos Socio-Políticos de la Globalización en América Latina”, en Revista Austral de Ciencias Sociales, n. ${ }^{\circ}$ 6, págs. 19-34, Valdivia, 2002, pág. 20. [En línea]. $<$ http://mingaonline.uach.cl/pdf/racs/n6/art02.pdf> [25 de julio de 2007].

19 Castells, Manuel; Laserna, Roberto: "The New Dependency: Technological Change and Socioeconomic Restructuring in Latin America", en Sociological Forum, volumen 4, n. 4, New York, December 1989, págs. 535-560.

20 Klein, Emilio; Tokman, Víctor E.: "La estratificación social bajo tensión en la era de la globalización”, en Revista de la CEPAL, n. ${ }^{\circ} 72$, Santiago, diciembre de 2000, págs. 8 y 9. [En línea]. $<$ http://www.eclac.cl/publicaciones/xml/8/19278/klein.pdf> [22 de julio de 2007].

21 Montoya, Jhon Williams: "Sistemas urbanos en América Latina: Globalización y urbanización”, en Cuadernos de Geografía, n. ${ }^{\circ}$ 13, Bogotá, 2004, pág. 53. [En línea]. $<$ http://agora.ulaval.ca/ jwmon/ciudadglobalCGEO2004.pdf> [15 de julio de 2007].

22 Borja, Jordi; Castells, Manuel; Belil, Mireia: "Descentralización y gestión urbana", en Lungo, Mario (coord.): Lo urbano: teoría y métodos. EDUCA, San José de Costa Rica, 1989. Citado por Díaz Orueta, Fernando: "La ciudad en América Latina: entre la globalización y la crisis", en América Latina Hoy, vol. 15, n. ${ }^{\circ}$ 015, Salamanca, abril de 1997, pág 9. [En línea]. <http://redalyc.uaemex.mx/redalyc/src/inicio/ArtPdfRed.jsp?iCve=30801502> [16 de julio de 2007].

23 Montoya, "Sistemas urbanos en América Latina: Globalización y urbanización”, pág. 52. 
En el plano urbanístico todo esto se ha reflejado, de manera parecida a lo sucedido en otras regiones del planeta, en la importancia estratégica adquirida por los márgenes de las principales regiones metropolitanas para la construcción de nuevos ambientes adecuados a la nueva economía urbana. ${ }^{24}$ Como consecuencia de ello, las periferias de las grandes ciudades latinoamericanas se han expandido absorbiendo pueblos y áreas rurales circundantes, conformando paisajes de fronteras difusas en los que coexisten grandes focos de miseria con nuevos escenarios que parecen tomar como paradigma la imagen urbana de los Ángeles o Miami. Esto último se refleja, especialmente, en la proliferación de grandes centros comerciales, complejos cerrados de viviendas de lujo y conjuntos empresariales integrados. ${ }^{25}$ Un ejemplo claramente ilustrativo de ello lo constituye Santiago de Chile, ciudad que ha desarrollado una nueva morfología territorial caracterizada por procesos de "suburbanización policéntrica" y multifuncional, y la concentración del comando del poder económico en determinados puntos de la capital. ${ }^{26}$

Junto a las periferias de las principales ciudades de la región, otros espacios que también reflejan el impacto que la globalización tiene sobre el medio urbano son los barrios y centros históricos y aquellos antiguos frentes costeros urbanos que han experimentado proyectos de intervención de gran envergadura, con el fin de conformar nuevos escaparates que hacen más interesantes sus respectivas ciudades para la atracción de inversiones y visitantes. Todo ello como consecuencia de la adhesión, durante la década de 1990, de varias ciudades latinoamericanas al ya mencionado fenómeno del city marketing.

Antes de pasar a analizar experiencias concretas de actuación en este sentido, es preciso destacar algunos factores que, desde nuestro punto de

24 Ossenbrugge, Jürgen: "Formas de globalización y del desarrollo urbano en América Latina”, en Iberoamericana. América Latina, España, Portugal: Ensayos sobre letras, historia y sociedad, n. ${ }^{\circ} 11$, Berlin, 2003, pág. 105. [En línea]. <http://www.iberoamericana.de/articulos-pdf/11Ossenbrugge.pdf $>$ [18 de julio de 2007].

25 De Mattos, Carlos A.: "Metropolización y suburbanización”, en Eure, vol. 27, n. ${ }^{\circ}$ 80, Santiago, mayo de 2001, págs. 5-8. [En línea] <http://www.scielo.cl/scielo.php?script= sci_arttext\&pid=S0250-71612001008000001\&lng=es\&nrm=iso >. [9 de octubre de 2007].

26 De Mattos, Carlos A.: "Reestructuración, Globalización, Nuevo Poder Económico y Territorio en el Chile de los 90", en De Mattos, Carlos A.; Hiernaux, Daniel; Restrepo, Darío: Globalización y Territorio. Impactos y perspectivas. Pontificia Universidad Católica de Chile, Santiago, 1998; De Mattos, Carlos A.: "Santiago de Chile, globalización y expansión metropolitana: lo que existía sigue existiendo?", en Eure, vol. 25, n. ${ }^{76}$, Santiago, 1999, págs. 29-56. [En línea] $<$ http://www.scielo.cl/scielo.php?script=sci_arttext\&pid=S0250-71611999007600002\&lng= es\&nrm=iso $>$ [11 de octubre de 2007]. 
vista, han dotado de cierta singularidad a este proceso en el ámbito latinoamericano. Por una parte, la adopción de estrategias que se inspiran en experiencias desarrolladas en Europa y Estados Unidos principalmente, ha encontrado en dicha región diferentes retos y problemáticas a los que hacer frente, como consecuencia del desigual reparto de la riqueza y los índices elevados de violencia urbana que caracterizan a numerosas ciudades de la región. Esto ha hecho que, a la hora de poner en marcha proyectos de recuperación de centros históricos o antiguos frentes portuarios, se haya optado, de una forma más aguda que en regiones con mayores niveles de desarrollo, por la privatización encubierta de espacios públicos, al quedar estos generalmente reservados para uso y disfrute casi exclusivo por parte de turistas y sectores de alto y mediano poder adquisitivo.

Por otro lado, a la hora de elaborar estrategias de marketing urbano destinadas a la construcción de imágenes atractivas para inversores y turistas, numerosas ciudades de la región han contado para ello con más inconvenientes que las europeas y norteamericanas. Especialmente, aquellas que se caracterizan por la existencia de elevados índices de violencia, falta de infraestructuras adecuadas, altos niveles de contaminación y una coyuntura económica inestable. ${ }^{27}$ Un ejemplo destacado en este sentido lo conforma el de la ciudad colombiana de Medellín. Conocida internacionalmente por sus elevados índices de criminalidad, sus autoridades han desarrollado ingentes esfuerzos por reducir el número de asesinatos, recuperar los espacios públicos como puntos de encuentro de sus ciudadanos y mejorar la imagen exterior de la ciudad. A pesar de los importantes logros obtenidos mediante un modelo de intervención basado en el concepto de Urbanismo Social, sigue siendo todavía difícil para muchos dejar de relacionar a Medellín con su pasado reciente más violento. ${ }^{28}$

27 En este sentido, resulta significativo el poco peso que las ciudades latinoamericanas tienen en la propaganda turística de la región, a pesar del rico legado patrimonial y la variada oferta cultural y ocio que muchas de ellas poseen. Cuando aparecen en las campañas de marketing, suelen hacerlo mostrando vistas urbanas en las que se retocan partes que pueden romper la visión idílica prometida y los habitantes aparecen en actitudes muchas veces caricaturizadas. Para más información sobre el caso brasileño consultar Luque Azcona, Emilio José y Zanirato, Silvia Helena: "Brasil: imágenes exportadas y turismo", en Amador Carretero, Pilar; Robledano Arillo, Jesús; Ruiz Franco, Rosario (eds.): Actas de las III Jornadas Imagen, Cultura y Tecnología, Editorial Archiviana, Madrid, 2005, págs. 339-349.

28 El modelo de Urbanismo Social comprende tanto la transformación física del espacio urbano y arquitectónico de la ciudad, como la intervención social, la gestión institucional y la participación comunitaria. Es en este contexto en el que las autoridades locales han visto al urbanismo y la arquitectura como instrumentos fundamentales en la transformación de la ciudad, que pueden contribuir a romper la espiral de violencia de los barrios. Entre las medidas adoptadas destacan algunas, como la exhibición de obras de arte contemporáneo en espacios públicos o la puesta en marcha del Plan municipal 


\section{Barrios y centros históricos}

En líneas generales, los centros históricos de numerosas ciudades latinoamericanas experimentaron un proceso de abandono por parte de los poderes públicos, tras la mudanza de los sectores medios y altos de la sociedad a las nuevas periferias a fines del siglo XIX y las primeras décadas del XX. Fue a partir de 1960 cuando estos espacios comenzaron a despertar cierto interés en algunos políticos, que vieron en ellos un importante potencial por su localización estratégica, la subida de los precios del suelo y el desarrollo del turismo. También de académicos y especialistas en patrimonio, que los interpretaron como escenarios de la "memoria colectiva de una nación o pueblo". ${ }^{29}$ No obstante, como consecuencia del aumento de la pobreza y de los índices de violencia en la región durante la década de 1980, numerosos barrios y centros históricos experimentaron entonces un empeoramiento de las condiciones de precariedad y hacinamiento existentes, junto con un deterioro del espacio publico ante el miedo de la población a socializar en ellos.

Hubo que esperar a los años noventa para que se pusieran en práctica proyectos de intervención de gran envergadura en barrios y centros históricos, en el contexto del fenómeno del marketing urbano al que aludimos anteriormente. Entre las ciudades de la región que han emprendido ambiciosos proyectos de intervención en sus respectivos centros históricos se encuentran algunas como Bogotá, Buenos Aires, Ciudad de México, Ciudad de Panamá, La Habana, Lima, Montevideo, Quito, Recife o Salvador de Bahia, principalmente. Si bien las medidas realizadas en esos espacios no siempre han respondido a efectos derivados de la globalización, tendremos en cuenta estas experiencias por haber contribuido, junto a otro tipo de iniciativas, a situar a esas ciudades en una posición más ventajosa de cara a la atracción de visitantes e inversores turísticos internaciona-

Parques Biblioteca, con el que se han generado espacios de estudio y formación y lugares de interacción comunitaria. Todo ello se enmarca dentro de una estrategia que busca, entre otras cosas, mejorar la imagen de la ciudad para consolidarla como un destino atractivo para el turismo y la celebración de convenciones nacionales e internacionales. Para ver algunas de las iniciativas emprendidas por las autoridades de la ciudad de Medellín, consultar la Web del Encuentro La transformación de Medellín. Urbanismo Social (2004-2007), en el siguiente enlace: <http://urbanismosocialmedellin.universia.net. co/presentacion.jsp? $\mathrm{m}=0 \& \mathrm{~s}=0>$ [ 1 de octubre de 2008].

29 Pancorbo de Sandoval, José A. "El marketing urbano como herramienta de apoyo en la gestión de los centros históricos", en Diseño y Sociedad, n. ${ }^{\circ}$ 18, Universidad Autónoma Metropolitana (Unidad Xochimilco), México, 2006, primavera, pág. 26. [en línea] <http://cyad.xoc.uam.mx/revistadys/03marketing.pdf> [17 de octubre de 2007]. 
les. Este hecho resulta especialmente llamativo para casos como los de $\mathrm{La}$ Habana, Recife o Salvador de Bahia, donde este tipo de emprendimientos ha sido visto por sus respectivos gobernantes como una herramienta importante para consolidar a sus ciudades en referentes turísticos de primer orden. ${ }^{30}$

El desarrollo del turismo, más que la función residencial, ha sido el principal impulsor de estas iniciativas, dado que los centros históricos latinoamericanos no conforman todavía, salvo excepciones como el recinto amurallado de Cartagena de Indias, Antigua en Guatemala o el barrio de Urca en Río de Janeiro, espacios atractivos en los que los sectores medios $\mathrm{y}$ altos quieran habitar, al ofrecerles las periferias urbanas mejores condiciones medioambientales y de seguridad. ${ }^{31}$

Desde el punto de vista metodológico, este tipo de iniciativas se han visto impulsadas principalmente por administraciones públicas locales, tras el protagonismo adquirido por éstas en el contexto del proceso de democratización y descentralización vivido a fines de los años ochenta e inicios de los noventa en la región. ${ }^{32}$ No obstante, la lógica privada de administración urbana ha desencadenado asimismo, durante las últimas décadas, la privatización de la gestión de centros históricos, al no contar los gobiernos locales con los recursos necesarios para la puesta en marcha de proyectos de intervención de gran envergadura. Como consecuencia de ello han aparecido instituciones que reciben diferentes nombres a lo largo del continente: corporaciones en Santiago, patronatos en Lima, empresas en Quito o fundaciones en México. ${ }^{33}$ En casos más específicos como el de La Habana, tras reconocerse por Decreto-Ley en 1993 como autoridad única para la conducción del proceso de rehabilitación de La Habana Vieja a la Oficina del Historiador de esa ciudad, dicha institución puso en marcha proyectos

$30 \mathrm{Al}$ respecto consultar Ochoa Alomá, Alina: Desafío de una utopía. Una estrategia integral para la gestión de salvaguarda de La Habana Vieja. 2 ed., Ediciones Boloña. Oficina del Historiador de La Habana, La Habana, 2002, pág 50; Mattos, Waldemar: Evolução histórica e cultural do Pelourinho, Editora Gráfica Barbero, Río de Janeiro, 1978, pág. 151; Mendes Zancheti, Silvio; Marinho, Geraldo; Lacerda, Norma: Revitalização do Barrio do Recife: Plano, Regulação e Avaliação. CECI-Editora da Universidade de Pernambuco, Recife, 1998.

31 Rojas, Eduardo: La preservación del patrimonio histórico urbano en América Latina y el Caribe. Una tarea de todos los actores sociales. Banco Interamericano de Desarrollo, Washington, DC, págs. 5 y 14. [En línea] <http://www.iadb.org/sds/doc/SOC125sp.pdf> [12 de marzo de 2007].

32 Carrión, Fernando: "Gestión o gobierno de los Centros Históricos", en Manejo y Gestión de los Centros Históricos. Conferencia de los I y II Encuentros Internacionales, La Habana Vieja, 2003 y 2004, Colección Arcos, Ediciones Boloña, La Habana, 2005, pág. 51.

33 Ibidem, pág. 49. 
turísticos con apoyo de capitales privados, cuyos beneficios se han reinvertido en la mejora de la infraestructura de la zona y en programas sociales. ${ }^{34}$ Junto a este tipo de instituciones han colaborado asimismo en proyectos de intervención en barrios y centros históricos otras de ámbito nacional, latinoamericano e internacional. Entre ellas destaca especialmente el Banco Interamericano de Desarrollo, que tras apoyar durante la década de 1970 proyectos financiados y ejecutados por organismos públicos, pasó en 1994 a respaldar exclusivamente aquellos que tuvieran probados beneficios económicos, induciendo a los gobiernos prestatarios a reformar instituciones y políticas relacionadas con esta materia. ${ }^{35}$

Uno de los programas más ambiciosos puestos en práctica por el BID ha sido el MONUMENTA, de manera conjunta con la UNESCO, el Ministerio de Cultura brasileño y el Instituto do Patrimônio Histórico e Artístico Nacional (IPHAN). Esta iniciativa tiene como objetivo la revitalización de manera sostenible de los principales conjuntos patrimoniales urbanos de Brasil. Para ello, incluye acciones que van desde las intervenciones de conservación y restauración hasta la aplicación de medidas educativas, gerenciales y administrativas que hagan posible "el retorno social y económico de las inversiones" realizadas. ${ }^{36}$

Fruto de las medidas aplicadas hasta la fecha en varias ciudades de la región, numerosos barrios y centros históricos han conseguido una mejora en sus infraestructuras y la recuperación de un patrimonio inmueble que se encontraba por lo general muy deteriorado. En este sentido, destaca por la amplitud del área intervenida el Pelourinho de Salvador de Bahia, sin bien esta actuación ha sido criticada por la destrucción ocasionada en el "pulmón" de algunas de las manzanas para la creación de nuevos espacios a modo de "plaza central o shopping mall", en los que realizar espectáculos musicales. También, por producir en la práctica una "idealización de la arquitectura antigua", como consecuencia del fortalecimiento de las características coloniales de aquellos inmuebles que sufrieron alteraciones durante los siglos XIX y XX, o el uso de una paleta de colores en las fachadas restauradas que no siempre se corresponden con la tradición arquitec-

34 Ochoa Alomá, Desafío de una utopía..., págs. 50 y 52. pág. 15.

35 Rojas, La preservación del patrimonio histórico urbano en América Latina y el Caribe,

36 El Programa Monumenta incluye en la actualidad a más de veinte ciudades de Brasil. UNESCO [en línea] <http://www.unesco.org.br/areas/cultura/destaques/monumenta/index_html/mostra_documento $>$ [19 de agosto de 2007]. 
tónica del lugar. ${ }^{37} \mathrm{El}$ uso exagerado de colores a la hora de restaurar fachadas de inmuebles se ha convertido en una especie de moda, de la que barrios como el de las Peñas en Guayaquil o la Boca en Buenos Aires, son algunos de los ejemplos más destacados.

Desde el punto de vista funcional, el interés por crear entornos atractivos y agradables para el turismo ha llevado en muchos casos a que las medidas adoptadas para la recuperación de barrios y centros históricos se hayan orientado a satisfacer las necesidades de los turistas, olvidándose de la población local. Este hecho se refleja en aspectos tales como la adaptación de edificios concebidos como viviendas para usos demandados por el turismo, el interés por erradicar el comercio ambulante con el objetivo de conformar una imagen más "civilizada" de dichos espacios y el escaso interés por fomentar el uso residencial, expulsándose incluso a la población residente de escasos recursos por considerarla incompatible para el desarrollo de la actividad turística. ${ }^{38}$

Con respecto al comercio callejero, en ciudades como La Habana, Lima, México, Morelia, Ouro Preto y Quito se ha procedido a su relocalización mediante la creación de zonas especiales para ello. ${ }^{39}$ En Quito, concretamente, la puesta en práctica del Plan de Modernización del Comercio Popular ha permitido la creación de centros comerciales populares, con servicios que han contribuido a la mejora de las condiciones de venta. ${ }^{40}$ De forma paralela, aunque escasas, ha habido algunas experiencias orientadas a resolver el problema de vivienda y recursos de la población residente. Entre ellas se encuentra la del Proyecto de Vivienda Social del Centro Histórico de Quito que, financiada por el BID, pretende contribuir a la preservación del valor histórico y monumental de la zona y favorecer el acceso de población residente de bajos recursos a viviendas dignas. ${ }^{41}$ También

37 Filgueiras Gomes, Marco Aurelio: "Historia, cultura y turismo en la ciudad contemporánea: algunas reflexiones sobre la rehabilitación del Pelourinho", en Revista Medio Ambiente y Urbanización, n. ${ }^{\circ}$ 55, Buenos Aires, julio de 2000, pág. 74.

38 Carrión, Fernando: "Lugares o flujos centrales: los centros urbanos", en Medio Ambiente y desarrollo., n. ${ }^{\circ}$ 29, Santiago de Chile, 2000, pág. 20.

39 Cabrales Barajas, Luís Felipe: "El centro histórico de Morelia: gestión social y revaloración del patrimonio", en Anales de Geografía de la Universidad Complutense, vol 22, Madrid, 2002, págs. 131- 156. [En línea] <http://www.ucm.es/BUCM/revistas/ghi/02119803/articulos/

AGUC0202110131A.PDF> [14 de mayo de 2007]; Mutal, Sylvio: "El futuro de las ciudades históricas", en Manejo y Gestión de los Centros Históricos..., pág. 31.

40 Moreira Ortega, Mónica: "La sostenibilidad económica de los Centros Históricos", en Manejo y Gestión de los Centros Históricos..., p. 96.

41 Carrión, "Lugares o flujos centrales: los centros urbanos", pág. 21. 
la de La Habana, donde junto con el fomento de la rehabilitación participativa se ha facilitado el realojo temporal en construcciones prefabricadas de aquellos vecinos cuyas viviendas son intervenidas ${ }^{42}$ Entre las ciudades que han puesto en marcha medidas orientadas a la resolución de esta problemática se encuentran otras como Cuzco, Lima, México y Montevideo. No obstante, en líneas generales, los logros obtenidos no han sido los esperados, ya sea por la falta de recursos para gestionar este tipo de iniciativas o por la huida voluntaria de residentes, que aprovechan las subvenciones de alquiler para realquilar sus casas a turistas o sectores de mayor poder adquisitivo que quieren residir en el centro. ${ }^{43}$

Uno de los casos más representativos de procesos de expulsión de población residente en centros históricos con el objetivo de favorecer el desarrollo de la actividad turística, lo conforma el ya mencionado del Pelourinho brasileño. Tras el traslado de su vecindario para la restauración de los inmuebles de la zona intervenida, únicamente un 5\% pudo regresar finalmente a sus antiguas viviendas, concretamente aquellos que desempeñaban actividades consideradas como compatibles con el desarrollo del turismo y la preservación de los inmuebles. ${ }^{44}$

Es cierto que la mayor parte del contingente que habitaba el Pelourinho no contaba con los recursos suficientes como para hacer frente a los costes de mantenimiento de los inmuebles. También, que dentro del mismo había sectores muy marginados socialmente, que contribuían a conformar una imagen peyorativa de la zona. No obstante, con la expulsión de

42 Rodríguez Alomá, Patricia: "Modelo de gestión para el desarrollo integral del Centro Histórico de La Habana”, en Manejo y Gestión de los Centros Históricos..., p. 82.

43 Para más información sobre este asunto consultar Coulomb, René: "Sostenibilidad social en los Centros Históricos", en Manejo y Gestión de los Centros Históricos..., p. 101; Mesías González, Rosendo y Suárez Pareyón, Alejandro (coords.): Los centros vivos, La Habana, Lima, México, Montevideo: alternativas de hábitat en los centros antiguos de las ciudades de América Latina, Programa Iberoamericano de Ciencia y Tecnología para el Desarrollo, La Habana y Ciudad de México, 2002.

44 Entre las posibles opciones que fueron ofertadas a los pobladores del Pelourinho estuvieron tanto la indemnización en metálico por mudarse, como la recolocación definitiva en un inmueble recuperado pagando alquiler con contrato jurídico válido, o la recolocación provisional en un inmueble hasta que finalmente fuera factible el traslado a una vivienda especialmente adaptada. Con respecto a las indemnizaciones, estas fueron calculadas según cada caso, dependiendo del tiempo de residencia en la zona, el tamaño de las familias o la situación jurídica de la ocupación. Según menciona Silvia Helena Zanirato, los criterios adoptados para el cálculo de las indemnizaciones buscaron proteger principalmente los intereses del gobierno, evitando que el mismo tuviera que pagar elevadas cantidades. Zanirato, Silvia Helena: "A restauração do Largo do Pelourinho: edificações tão bonitas de se ver, histórias não tão bonitas de se contar", en Dimensões. Revista de História da UFES, n. . 16, Vitória, 2004, págs. 332 y 333 . 
esos grupos no sólo empeoraron en muchos casos las condiciones de vida de estas personas, también se impidió que el barrio mantuviese su vida propia y la riqueza cultural de sus vecinos, que durante los años 80 habían contribuido a la afirmación de dicha zona como barrio negro, pasada la proliferación de blocos afro o grupos musicales integrados principalmente por afrodescendientes. ${ }^{45}$

Este tipo de iniciativas ha ocasionado, tanto en el Pelourinho como en aquellos centros históricos en los que ha perdido peso la función residencial, que las antiguas construcciones concebidas como viviendas hayan pasado a estar ocupadas por bares, restaurantes, tiendas, galerías de arte o museos, en su mayor parte orientados al sector turístico. Esto ha repercutido en una dependencia excesiva de esa actividad para el mantenimiento de estos espacios, que como consecuencia de ello ya no constituyen lugares de encuentro cotidiano para las poblaciones locales. En algunos casos se ha tratado incluso de potenciar de manera consciente esto último, con el objetivo de conformar espacios seguros para el turista, poniendo en práctica medidas de vigilancia policial y de separación étnica y social para impedir el acceso a estos recintos de población sospechosa de poder protagonizar robos. ${ }^{46}$

No obstante, en lo que respecta al caso concreto del Pelourinho, es preciso aclarar que en los últimos años se ha producido un cambio en las políticas aplicadas por las autoridades que gestionan la zona. Por una parte, se ha permitido que el costoso programa de animación cultural popular que desarrolla el gobierno en la zona sea disfrutado por expobladores y vecinos de baja renta, produciéndose con ello una "reapropiación virtual" del barrio por estos grupos. En este sentido, las autoridades han cambiado la concepción original dada al proyecto, concebido ahora como forma de esparcimiento popular que anima el barrio y un posible recurso para el incremento de votos en las elecciones. Las autoridades han aceptado también el uso habitacional como vía para la rehabilitación del barrio. Para ello se van poniendo en marcha algunas iniciativas, como la del proyecto 'Rememorar' que, coordinado por la Secretaria de Desenvolvimento Urbano del Estado de Bahia junto con la Prefectura de Salvador y con el 71 y 75.

45 Filgueiras Gomes, "Historia, cultura y turismo en la ciudad contemporánea...”, págs. 70,

46 Para el caso concreto del Pelourinho consultar Zanirato, Silvia Helena: "As politicas de preservação e de usufruto do Patrimônio Cultural: o Centro Histórico de Salvador, como um estudo de caso", en Pós - história. Revista de posgraduação em História, Assis, 2001, pág. 164. 
apoyo de la Caixa Econômica Federal, contempla la recuperación de caserones de los siglos XVII y XVIII para la construcción de apartamentos de dos habitaciones. En principio, las unidades habitacionales son financiadas para funcionarios públicos del Estado y adquiridas a través de un sistema de arrendamiento, con un plazo de quince años para proceder al pago de las mismas ${ }^{47}$ Esto supone un giro positivo de cara a conseguir un Pelourinho multifuncional y menos dependiente de los ingresos generados por la actividad turística.

\section{Antiguos frentes costeros urbanos}

A diferencia de lo sucedido con barrios y centros históricos, las iniciativas tendentes a la conformación de nuevos "escaparates" urbanos a partir de la recuperación de antiguos frentes costeros urbanos han contado con un escaso desarrollo en el ámbito latinoamericano. En este sentido, destacan principalmente experiencias como las de Buenos Aires y Guayaquil, junto a otras de menor envergadura, como la de Belem do Pará, por ejemplo.

En el caso de Buenos Aires, con la remodelación de Puerto Madero, localizado junto al centro histórico de la ciudad, se quiso poner fin a su situación de abandono, tratándose para ello tanto de recomponer su carácter urbano, como de promover el alojamiento de actividades terciarias y de tipo residencial y acercar la ciudad al río. ${ }^{48}$ En Guayaquil, con el Proyecto Malecón 2000 para la renovación del malecón Simón Bolívar, el gobierno local pretendió impulsar el rescate del deteriorado centro comercial y bancario de la ciudad y transformar la imagen peyorativa que concebía al conjunto urbano como violento, sucio y sin atractivo turístico alguno. Con ésta y otras medidas se ha buscado consolidar a Guayaquil como destino turístico, puerto de entrada a las islas Galápagos, centro de conferencias y eventos de relevancia internacional. ${ }^{49}$

47 Azevedo, Paulo Ormindo de: "El Pelourinho de Bahia, cuatro décadas después", en ICONOS, Revista de Ciências Sociales, Quito, pág. 51. [En línea]. <http://www.flacso.org.ec/docs/ i20ormindo.pdf $>$ [19 de noviembre de 2006]. de 2007].

48 Puerto Madero [en línea] <http://www.puertomadero.com/historia6.cfm> [17 de octubre

49 Fundación Malecón 2000 [En línea] <http://www.malecon2000.org/fundacionmalecon 2000/historia.asp> [11 de octubre de 2007]. 
Con respecto a los actores involucrados en este tipo de iniciativas, en la capital argentina el Ministerio de Obras y Servicios Públicos, el Ministerio del Interior y la Municipalidad de la Ciudad de Buenos Aires firmaron en 1989 el acta de constitución de una sociedad anónima, la Corporación Antiguo Puerto Madero S A. En ella, las instituciones mencionadas participaban como socios igualitarios. Las de ámbito nacional transfirieron en propiedad a la mencionada corporación las 170 hectáreas del lugar, que poseían jurisdicciones superpuestas entre la Administración General de Puertos, la empresa Ferrocarriles Argentinos y la Junta Nacional de Granos, al tiempo que el gobierno local quedó como responsable de la reglamentación de la normativa de desarrollo urbano. Poco después se procedió a la aprobación de un Plan Maestro que proporcionara las pautas generales y una estructura básica para regir los diversos emprendimientos dentro del área. ${ }^{50}$

En el caso de Guayaquil, el gobierno local impulsó la creación de la Fundación Malecón 2000, entidad de derecho privado presidida por el alcalde y conformada por algunas de las instituciones públicas y privadas más relevantes de la ciudad. Desde su comienzo en enero de 1997 se ha encargado de la propuesta, ejecución y administración del proyecto Malecón 2000 y de otros espacios públicos de Guayaquil, con el fin de "permitir que la ciudad se reencuentre con estos espacios como el eje principal de su desarrollo social, cultural y productivo". Para ello, su modelo de gestión se ha inspirado en experiencias exitosas como las de Barcelona, Buenos Aires o Bilbao. ${ }^{51}$ Un aspecto original relativo al modelo de financiación del Proyecto Malecón 2000 lo conforma la ley de donaciones, medida a través de la cual el contribuyente del impuesto nacional de renta o de ingreso selecciona el beneficiario del $25 \%$ de este impuesto entre el Gobierno Central y gobiernos o proyectos locales. ${ }^{52}$

50 Corporación Antiguo Puerto Madero, S A.: Un modelo de gestión urbana (1989-1999), Ediciones Lariviére, Buenos Aires, 1999.

51 Fundación Malecón 2000 [En línea] <http://www.malecon2000.org/fundacionmalecon 2000/historia.asp> [11 de octubre de 2007].

52 En el caso concreto del Malecón 2000, el proyecto tuvo un coste inicial estimado de $\$ 60$, 000,000.00. Para su financiamiento se estableció que un $60 \%$ del importe total sería recaudado por donaciones hechas por personas naturales o empresas que autorizaron que se donase la cuarta parte del Impuesto a la Circulación de Capitales del $0.8 \%$ que ellos pagaron al Servicio de Rentas Internas por todas sus transacciones bancarias. El $20 \%$ mediante créditos bancarios y el otro $20 \%$ por venta de derechos de concesión. Municipalidad de Guayaquil [En línea] <http://www.guayaquil.gov.ec/1.gye> [1 de agosto de 2007]. 
Como consecuencia de las medidas desarrolladas en Puerto Madero, la ciudad de Buenos Aires ha ganado nuevos espacios públicos y cuenta con otro escaparate que la hace más atractiva de cara al turismo y la inversión inmobiliaria. Todo ello gracias a la mejora sustancial de las infraestructuras y la recuperación del patrimonio inmueble existente en la zona. En este sentido, se han restaurado antiguos edificios portuarios, creado nuevas calles, avenidas, parques y plazas e incorporado obras realizadas por arquitectos de prestigio internacional como el puente de la Mujer, del arquitecto Santiago Calatrava. Asimismo, se han acondicionamiento espacios para oficinas, instalaciones universitarias, comercios, hoteles de lujo, congresos y complejos residenciales orientados a sectores de alto poder adquisitivo. ${ }^{53}$ Puerto Madero ha pasado así de constituir una barrera que obstaculizaba el encuentro del río con la ciudad, a conformarse en una nueva centralidad que conecta Buenos Aires con lo global. Especialmente tras haberse propiciado con lo expuesto el desarrollo de otras actuaciones en el entorno más inmediato, concretamente en Catalinas Norte y en el área de Plaza de Roma, marco escogido por varias multinacionales para la instalación de sus oficinas.

Mientras tanto, en Guayaquil, las obras del Malecón 2000, iniciadas en 1998, han permitido la recuperación para la ciudad de algunos de sus monumentos más relevantes, entre ellos la Rotonda, la Torre Morisca y el Mercado del Sur. También van dotando a la ciudad de nuevos espacios verdes, comerciales y culturales, entre ellos el Museo Antropológico y de Arte Contemporáneo del Banco Central del Ecuador (MAAC) y el Teatro IMAX, el primero de sus características en Sudamérica. El recinto, con unos dos kilómetros y medio de extensión, se encuentra cerrado en su perímetro y cuenta con varios portones de acceso vigilados y modernos sistemas de control. Con todo ello se ha conformado un parque urbano que devuelve a Guayaquil su relación perdida con el río Guayas y que constituye un incentivo para la regeneración urbana del centro de la ciudad. ${ }^{54}$ Asimismo, se ha contribuido a mejorar de forma sustancial la imagen externa de Guayaquil de cara a la atracción de inversiones y turis-

53 Borthagaray, Juan Manuel: "El desarrollo urbano del antiguo Puerto Madero en la ciudad de Buenos Aires”, en Diseño y Sociedad, n. ${ }^{\circ}$ 18, México, primavera de 2006, pág. 66. [en línea] $<$ http://cyad.xoc.uam.mx/revistadys/08puertomadero.pdf> [17 de octubre de 2007].

54 Municipalidad de Guayaquil [en línea] <http://www.guayaquil.gov.ec/61.gye > [1 de agosto de 2007]; Fundación Malecón 2000 [En línea] <http://www.malecon2000.org/fundacionmalecon2000/ historia.asp> [11 de octubre de 2007]. 
tas. ${ }^{55}$ También a que sus propios habitantes recuperen la autoestima ciudadana. ${ }^{56}$

De manera parecida a lo sucedido con varios de los barrios y centros históricos intervenidos, en Puerto Madero y el Malecón 2000 es posible encontrar también la puesta en práctica de medidas que suponen una privatización encubierta de espacios públicos. En el caso de la capital argentina, esto se ha reflejado tanto en el intento de vender patrimonio público para el desarrollo de negocios inmobiliarios, ${ }^{57}$ como en la orientación inicial del proyecto a grupos de elevado poder adquisitivo, aspecto este último que ha impedido una mayor interacción de Puerto Madero con las zonas cercanas más pobres localizadas al sur. ${ }^{58}$ No obstante, la posibilidad de adquirir bebidas y alimentos en el recinto a precios más accesibles en determinados establecimientos, ha propiciado que el público que actualmente acude a pasear por la zona sea más variopinto y diverso que el que lo hacía dos años atrás. En el caso de Guayaquil resulta especialmente llamativa la falta de transparencia en cuestiones relativas a la financiación y la gestión de proyectos, por contar fundaciones como la de Malecón 2000 con un régimen privado que les excluye de algunas obligaciones estatales que garantizan el derecho a la información por parte de los ciudadanos. ${ }^{59}$ También, el control

55 En este sentido, resulta bastante ilustrativo el suplemento dedicado a Guayaquil que la revista USA TODAY publicó en julio de 2006, en el que describe el que considera como "the largest and fastest urban renewal process in Latin America", que ha transformado "a rundown port into a contemporary city of opportunity". United World: "Guayaquil, Ecuador's largest city reinvents itself", en Our World, Washington DC, 2006, 6 de Julio. [En línea]. <http://www.unitedworld-usa.com/pdf/ guayaquil.pdf>. [30 de julio de 2007].

56 Al respecto consultar el artículo del Diario ecuatoriano Hoy titulado "La regeneración eleva la autoestima", publicado el 25 de julio de 2006.

57 Esto es lo que ha sucedido, por ejemplo, con los terrenos del Campo de Deportes del Colegio Nacional de Buenos Aires. Para más información consultar, entre otros, el artículo del Diario argentino Clarín titulado "Postergan la definición sobre la venta de un predio de la UBA en Puerto Madero" del 21 de diciembre de 2005.

58 Entre los conflictos generados en este sentido, destaca el suscitado por la inauguración de un comedor comunitario en pleno Puerto Madero por el movimiento piquetero de Raúl Castells en el 2006, en un local cedido por uno de los empresarios de la zona. Dieciséis meses después de su apertura fue clausurado por la justicia porteña, alegando deficiencias "en materia de seguridad, higiene y habilitación". Para Castells se buscaba con ello "ocultar ante los turistas que visitan Puerto Madero la pobreza creciente del pueblo argentino". Al respecto consultar, entre otros, los artículos del Diario argentino Clarín titulados "Castells inauguró su comedor comunitario en Puerto Madero tras haber pasado por Tribunales", del 9 de marzo de 2006, y "Clausuraron el comedor de Castells en Puerto Madero", del 26 de julio de 2007.

59 United Nations Development Programm / Municipalidad de Guayaquil: Experiencia Guayaquil, Acción Social, Dirección de Acción Social y Educación. Dirección de Salud e Higiene, Guayaquil, 2004, pág. 24. [En línea]. <http://www.logos.undp.org/fileadmin/docs/Experiencia_ Guayaquil/Libro_Guayaquil.pdf> [31 de Julio]. 
que compañías privadas tienen sobre espacios públicos renovados a la hora de determinar el acceso y el tipo de comportamientos que los usuarios deben tener en ellos, a pesar de que estos se anuncian como puntos de encuentro para la ciudadanía. ${ }^{60}$ En este sentido, se ha impedido el acceso a las zonas renovadas de jóvenes de aspecto sospechoso o con ropas provocativas, homosexuales y transexuales, así como trabajadores informales que tratan por ello de sobrevivir en los márgenes de esas zonas. Dentro del recinto del Malecón 2000, por ejemplo, las parejas no pueden besarse ni "comportarse de manera inapropiada", ni los peatones en general acostarse en los bancos o sentarse al lado de las fuentes.

\section{A modo de conclusión}

El análisis desarrollado en el presente artículo nos permite contextualizar, tanto desde el punto de vista histórico como metodológico, iniciativas de reestructuración y revalorización de espacios urbanos que generalmente se analizan de forma aislada o comparando experiencias de este tipo desarrolladas en diferentes ciudades del planeta. Como hemos podido comprobar, esos procesos de cambio de espacios urbanos no constituyen un fenómeno novedoso. Ya se dio en el pasado y, de manera similar a cómo sucede hoy, respondieron en su momento a los intereses de los grupos de poder que los impulsaron y contribuyeron en muchos casos a transformar, de manera forzada, el carácter identitario de las zonas intervenidas. A diferencia de las anteriores, las experiencias de este tipo desarrolladas durante las últimas décadas han buscado, en ocasiones, el situar a determinadas ciudades en una posición ventajosa de cara a la atracción de inversiones y visitantes en el contexto de un mundo cada vez más globalizado.

En América Latina comenzaron a desarrollarse con este último objetivo algunas experiencias, a partir de inicios de la década de 1990. Entre los ejemplos más paradigmáticos en este sentido se encuentran los ya comentados del Malecón 2000 de Guayaquil, Puerto Madero en Buenos Aires o la zona del Pelourinho en Salvador de Bahia. Las tres experiencias se inspiran en iniciativas similares llevadas a cabo en ciudades de Europa y Estados Unidos y, más allá de los logros obtenidos, las inter-

60 Garcés, Chris: "Exclusión constitutiva: las organizaciones pantalla y lo anti-social en la renovación urbana de Guayaquil”, en ICONOS, n. ${ }^{\circ}$ 20, Quito, 2004, págs. 57 y 58. 
venciones llevadas a cabo han contribuido a afianzar en estas urbes algunos de los efectos característicos que la globalización tiene sobre el medio urbano.

Uno de ellos es la separación de los habitantes en "excluidos" e "incluidos" mediante el desarrollo de procesos de gentrificación que se apropian de recursos y espacio público. En este sentido, esta exclusión, que también se produce en los países más desarrollados, se ha llevado a extremos mayores en algunos de los casos analizados. Especialmente en Guayaquil y Salvador de Bahia, donde los índices de violencia existentes han llevado a que se impida el uso y disfrute de los espacios intervenidos, que son públicos, a los sectores sociales más desfavorecidos. En este sentido, ya mencionamos que en el caso del Pelourinho se ha producido recientemente un cambio en esta tendencia, permitiendo las autoridades que estos grupos participen, junto a los turistas, de las actividades culturales organizadas en la zona.

Otro de los efectos característicos de la globalización ha sido la relativa tendencia a la homogeneización de modos de consumo y estilos de vida. En este sentido, el empleo de criterios y estrategias similares a la hora de intervenir centros históricos en contextos geográficos y culturales diferentes, terminan por convertir estos espacios en una especie de parques temáticos para turistas, tras la idealización del paisaje urbano y arquitectónico que les caracteriza, la expulsión de la población de menores recursos y la sustitución del comercio local por establecimientos de firmas multinacionales. Por otra parte, el ejemplo de Puerto Madero también es significativo en este punto, al no diferir la arquitectura y los nuevos usos incorporados en ese ámbito de los que podemos encontrar en otras ciudades de Europa y Estados Unidos. Prácticamente, sólo los establecimientos gastronómicos de carne existentes en la zona pueden hacernos sentir que nos encontramos en Argentina.

El tercero sería la conformación de nuevas centralidades que conectan lo local con lo global, como sucede con Puerto Madero y las zonas aledañas, donde han instalado sus sedes nacionales diferentes empresas multinacionales que operan en el país. En los casos de Guayaquil y Salvador, las experiencias analizadas no han actuado en el mismo sentido pero sí han contribuido a la mejora de la imagen exterior de cara al desarrollo del turismo y, para el caso de Guayaquil, ha logrado también que sus propios habitantes e inversionistas extranjeros tengan una imagen más positiva de la ciudad. 
Ante la situación descrita, el gran reto que se plantea a las instituciones implicadas en la gestión de proyectos como los expuestos en el ámbito latinoamericano, es lograr conciliar las necesidades demandadas por la población local con las derivadas del proceso de globalización. En este sentido, el desarrollo de un turismo sostenible que pueda contribuir a la mejora de las condiciones de vida de los sectores más marginados es una posible vía de trabajo. Para ello es importante respetar el carácter histórico y la identidad de los espacios intervenidos, evitando la idealización del paisaje urbano y arquitectónico y fomentando en ellos el uso residencial de diferentes grupos sociales, incluidos los más desfavorecidos. Con esto se evitará que los sectores más marginados continúen empeorando sus condiciones de vida y se contribuirá a la conformación de escaparates urbanos de mayor atractivo por su singularidad, al mantener su vida propia y la riqueza cultural que les caracteriza. Ante esto, muchos podrían pensar que este tipo de planteamientos no son viables en sociedades que se caracterizan por la existencia de grandes desigualdades y elevados índices de violencia. No obstante, avances como los experimentados en Medellín con el desarrollo del Urbanismo Social, el giro dado recientemente por las autoridades de Bahia a la hora de gestionar el Pelourinho o la consolidación de Puerto Madero como lugar de esparcimiento y ocio de diferentes sectores sociales y de turistas, podrían mostrar lo contrario. 